\title{
231679
}

UCRL-JC-127273

PREPRINT

\section{Stacked Insulator Induction Accelerator Gaps}

\author{
T. L. Houck, G. A. Westenskow \\ J.-S. Kim, S. Eylon, E. Henestroza, Fusion \& Accelerator Research \\ S. S. Yu, D. Vanecek, LBNL
}

This paper was prepared for submittal to the

1997 Particle Accelerator Conference

Vancouver, B. C. Canada

May 12-16, 1997

May 1997

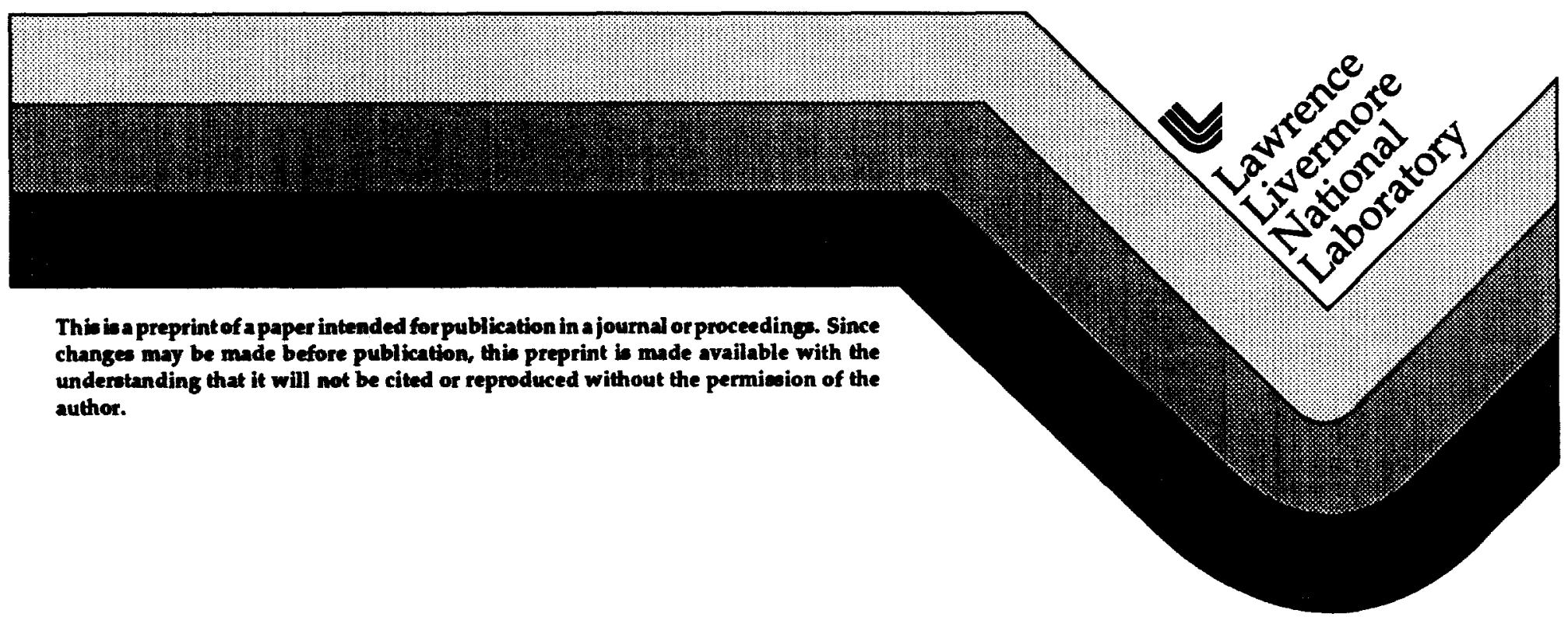




\section{DISCLAIMER}

This document was prepared as an account of work sponsored by an agency of the United States Government. Neither the United States Government nor the University of California nor any of their employees, makes any warranty, express or implied, or assumes any legal liability or responsibility for the accuracy, completeness, or usefulness of any information, apparatus, product, or process disclosed, or represents that its use would not infringe privately owned rights. Reference herein to any specific commercial product, process, or service by trade name, trademark, manufacturer, or otherwise, does not necessarily constitute or imply its endorsement, recommendation, or favoring by the United States Government or the University of California. The views and opinions of authors expressed herein do not necessarily state or reflect those of the United States Government or the University of California, and shall not be used for advertising or product endorsement purposes. 


\title{
STACKED INSULATOR INDUCTION ACCELERATOR GAPS
}

\author{
T.L. Houck, G.A. Westenskow, Lawrence Livermore National Laboratory, Livermore, CA 94551 \\ J.-S. Kim, S. Eylon, E. Henestroza, Fusion and Accelerator Research, San Diego, CA 92122 \\ S.S. Yu, D. Vanecek, Lawrence Berkeley National Laboratory, Berkeley, CA 94720
}

\begin{abstract}
Stacked insulators, with alternating layers of insulating material and conducting film, have been shown to support high surface electrical field stresses. We have investigated the application of the stacked insulator technology to the design of induction accelerator modules for the Relativistic-Klystron Two-Beam Accelerator program. The if properties of the accelerating gaps using stacked insulators, particularly the impedance at frequencies above the beam pipe cutoff frequency, are investigated. Low impedance is critical for RelativisticKlystron Two-Beam Accelerator applications where a high current, bunched beam is transported through many accelerating gaps. An induction accelerator module designs using a stacked insulator is presented.
\end{abstract}

\section{INTRODUCTION}

Induction accelerators are a unique source for highcurrent, high-brightness, charged particle beams. Induction accelerators are used to drive very high-power microwave sources such as free electron lasers and relativistic klystrons, as intense-xray sources for radiographic applications, and as intense beam sources for material processing. Induction accelerators also are expensive, and the higher energy induction accelerators have been limited to major national laboratories. For these accelerators to become commercially viable, the basic unit of the accelerator, the induction module, must be made more compact, efficient, and less costly.

Novel accelerating gap designs for induction modules based on developing insulator technology provide an opportunity to move induction accelerators from expensive research devices into commercial applications. These novel high-gradient insulators (HGI's), comprised of finely spaced, alternating layers of dielectric and metal, have demonstrated much greater (factors of 1.5 to 4 times) vacuum surface flashover capability than insulators made from a uniform dielectric $[1,2]$. The HGIs also maintained similar capability in the presence of a cathode and electron beam [3]. The high field stress level in the presence of a beam can permit greatly simplify designs for accelerating gap. In typical induction accelerator designs [4], the gap is shaped to accommodate an extended insulator that is hidden from line-of-sight view of the beam. The shape of the gap must be carefully designed to minimize field stress on the vacuum surfaces.

The rf characteristics of the gap are an important consideration. The transverse interaction impedance of the gap with the beam can lead to collective beam instabilities. The longitudinal impedance can also be an important parameter in some applications, e.g. RKTBA's. Recent measurements $[5,6]$ of simplified gaps including stacked insulators have shown that the HGr's can improve the of characteristics over that of a solid insulator.

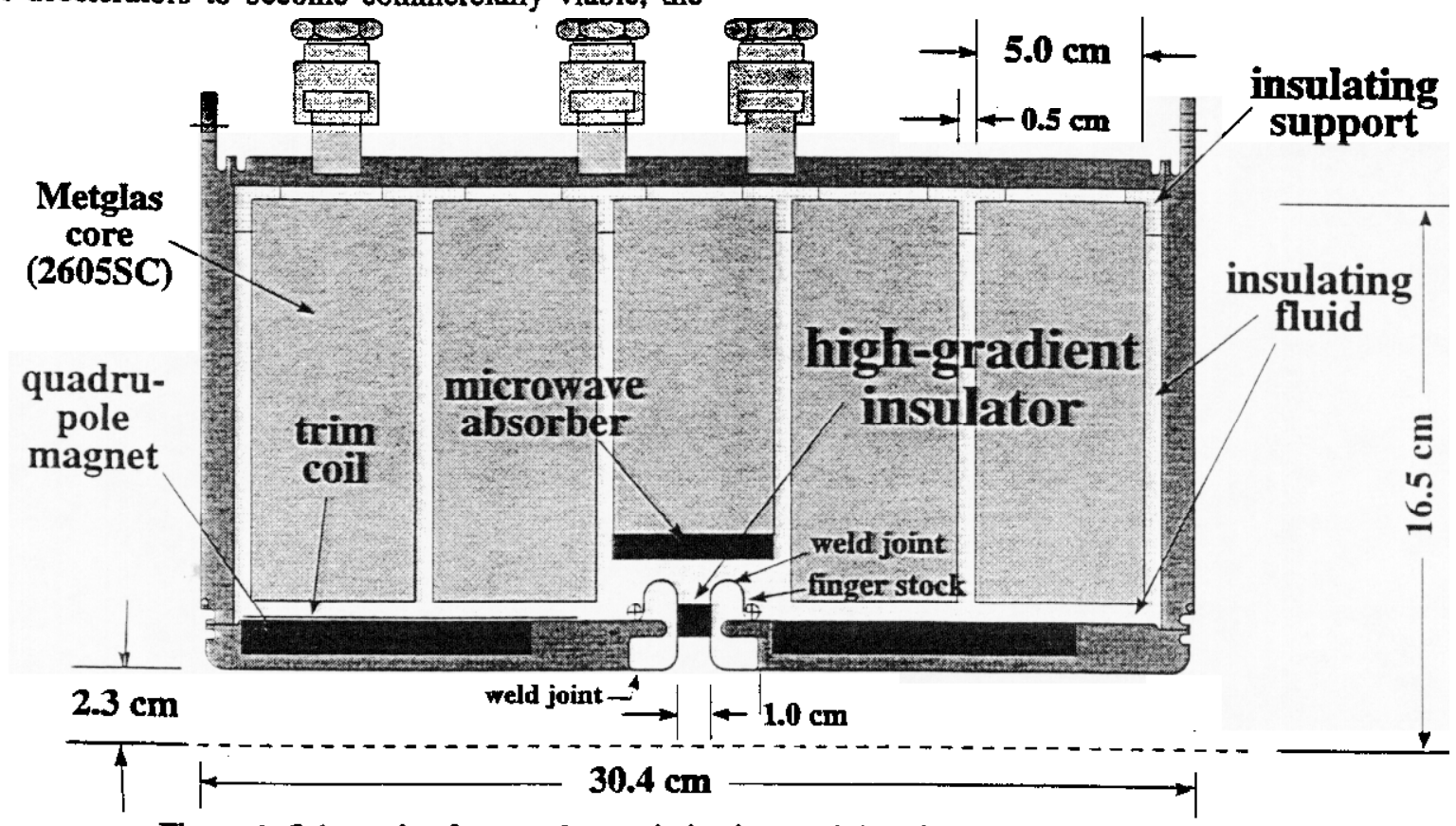

Figure 1. Schematic of an accelerator induction module using a high-gradient insulator. 


\section{ACCELERATOR MODULE DESIGN}

We have designed an induction module suitable for use in the proposed TBNLC relativistic klystron [7]. The performance specifications for the TBNLC induction module are both comprehensive and demanding, and, prior to our design, no module design had met all the required specifications. An illustration of our module design is shown in Figure 1. The design must also be consistent with the beam focusing scheme that uses periodic quadrupole magnets.

\subsection{RF Characteristics}

The transverse impedance for a cavity can be estimated from $Z_{\perp}=120 \eta \mathrm{w} / \mathrm{b}^{2}$ ohms/m [8], where $w$ is the gap width and $b$ is the beam pipe radius. $\eta$ is a design quality factor of order unity and determined by the de-Qing of the cavity. In our design, $w=1 \mathrm{~cm}$ and $b=2.3 \mathrm{~cm}$. The desired $Z_{\perp}$ is $\leq 5,400 \Omega / m$. This leads to a modest value of 2.3 for $\eta$ (most designs have $1.3<\eta<1.9$ ). The desired longitudinal impedance, $Z_{L}$, is less than $2.5 \Omega$ at $11.4 \mathrm{GHz}$, a difficult value to achieve. Changinging $\eta$ to reduce $Z_{\perp}$ tends to increase the minimum value of $Z_{L}$.

The transverse impedance was initially studied with URMEL to determine the field structure of the trapped dipole modes. This information was used to determine appropriate locations for placement of absorbing (de-Qing) material within the cell. An induction module design code, AMOS, was then used to calculate the impedances of the module with ferrite absorbers. Results of AMOS calculations are shown in Fig. 2 and 3. $Z_{\perp}$ decreases to a negligible level above $7 \mathrm{GHz} . \mathrm{Z}_{\mathrm{L}}$ is shown over the range of interest. The power spectrum of the modulated current is only significant at $11.424 \mathrm{GHz} \pm 10 \mathrm{MHz}$.

\subsection{Transverse Beam Dynamics}

Transverse beam dynamics were examined using AMOS generated wakefields in the MBBU code [9]. The dipole wakefield associated with the impedance in Fig 2. is shown in Fig. 4. Shown are the transverse wake-fields of a $11.4 \mathrm{GHz}$ gaussian bunch with standard deviation length of $1.875 \mathrm{~mm}$ for the distribution. For clarity wakefields up to about 114 bunch spacings are shown.

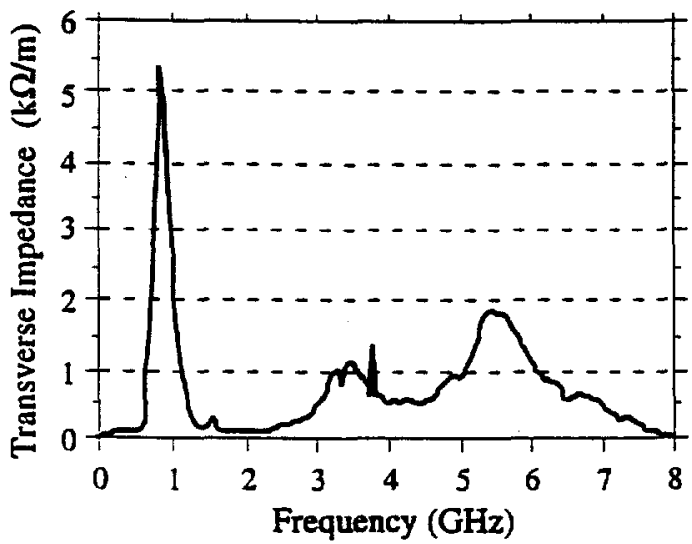

Figure 2. Transverse impedance spectrum.

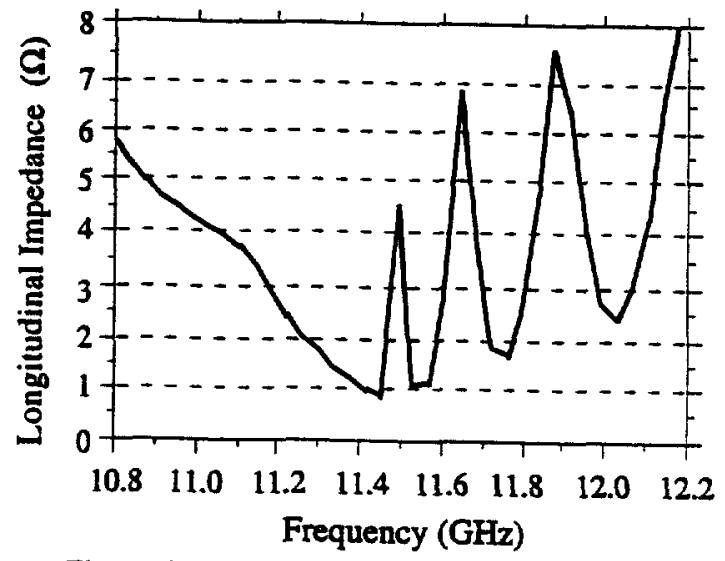

Figure 3. Longitudinal impedance spectrum.

The open circles indicate the wakefields at centers of bunches. Higher wakefields are seen for the shorter bunches. Since a small increase in wakefield magnitude results in a cumulative BBU over many bunches and traveling many structures, the bunch length needs to be compromised with respect to BBU.

In Figs. 5 and 6 we present the BBU results using the MBBU code for the wakefield of the Gaussian bunch (solid line in Fig.4). The initial beam displacements were assumed to be uniform with no transversal momentum for all cases. An average beam current of $600 \mathrm{~A}$ with energy of $10 \mathrm{MeV}$, and betatron length of $2 \mathrm{~m}$ are considered.

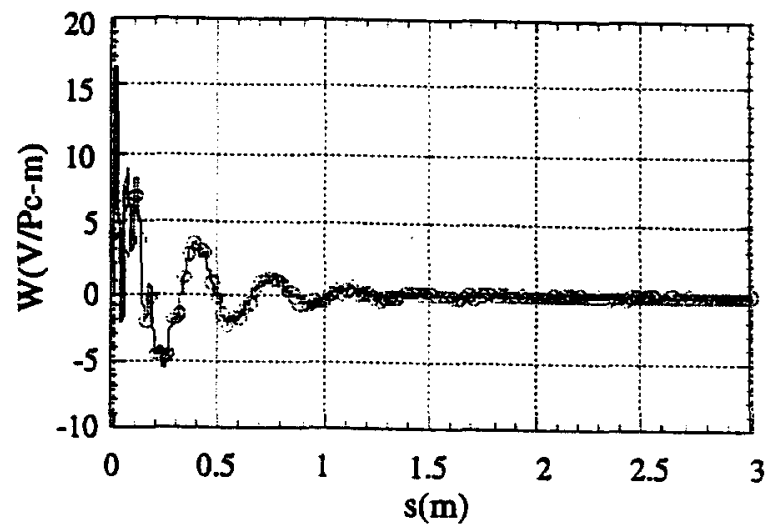

Figure 4. Dipole wakefield for impedance in Fig. 2.

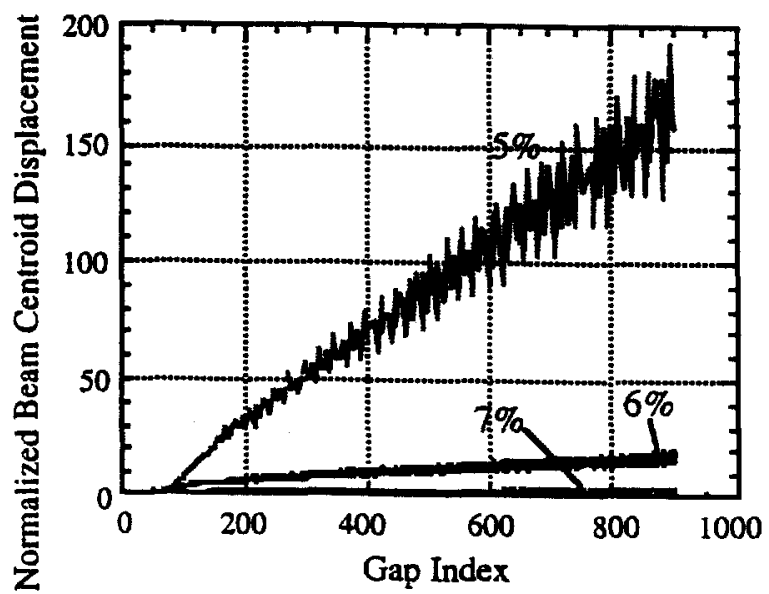

Figure 5. BBU growth for different energy spreads. 


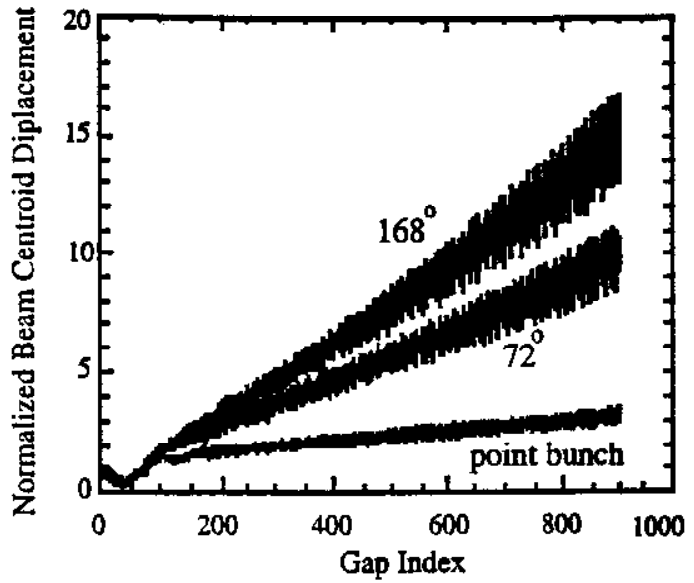

Figure 6. Bunch size and self-wakefield effects.

Fig. 5 summarizes the BBU growth over 900 gaps for various energy spreads. For energy spreads $\geq \pm 6 \%$, the BBU is reduced to an acceptable level over 900 structures by Landau damping. In Fig. 6 the finite size of a bunch and the wakefield effect within a bunch are included. Each bunch is uniformly divided into 3 slices over $72^{\circ}$ and by 7 slices over $168^{\circ}$. All cases have $\pm 7 \%$ energy spread within each slice, which is represented by 30 microparticles per slice.

\subsection{Electric Field Stresses}

Poisson was used to determine electrical field stresses in the gap. An equi-potential plot for the gap design is shown in Fig. 7. The highest vacuum electrode fields are $120 \mathrm{kV} / \mathrm{cm}$ along the entrance to the gap and are acceptable for 300 ns pulses [10]. The electric field across the stacked insulator is a uniform $100 \mathrm{kV} / \mathrm{cm}$. We expect that the stacked insulator will support nearly 200 $\mathrm{kV} / \mathrm{cm}$ without breakdown. The method of assembling the gap in the cell readily allows for special treatment, e.g. electropolishing, of the high field stress surfaces if a greater safety margin is desired. On the oil side of the gap, the highest surface electric field is $135 \mathrm{kV} / \mathrm{cm}$ near the top of the gap.

\subsection{Mechanical Design Considerations}

The insulator is comprised of seven $1 \mathrm{~mm}$ layers of polycarbonate alternating with six $0.5 \mathrm{~mm}$ layers of conductor. This configuration was also used in the AMOS and Poisson simulations. The insulator fabrication procedure will incorporate additional, larger conductors on either end that are used for mounting the insulator into the gap. These two conductors will be preformed with a $0.5 \mathrm{~cm}$ radius of curvature, $90^{\circ}$ bend on the inner radius and weided to the beam line at a point of low surface electric field stress to create the vacuum seal. On their outer radius, the conductors have a $180^{\circ}$ bend terminating in an electrical slip connection that rides on the magnet housing. This arrangement reduces stress on the insulator due to module housing motion or thermal expansion.

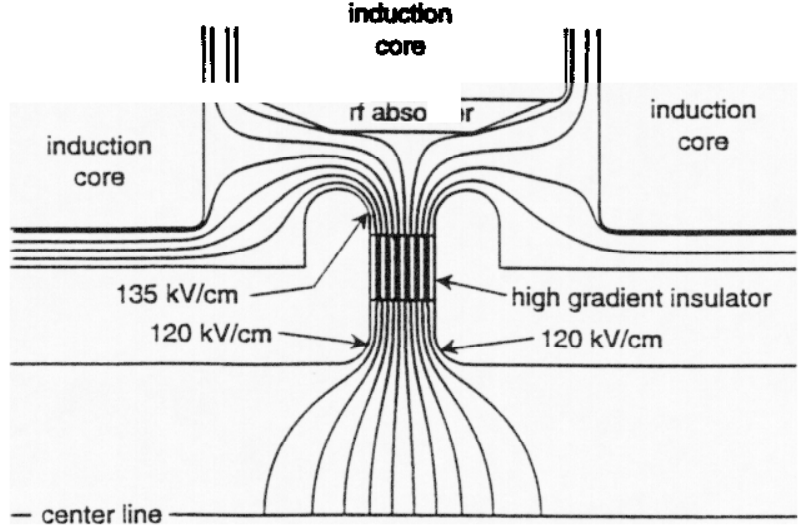

Figure 7. Equi-potentials lines in vicinity of module gap.

The microwave absorber is segmented ferrite sections epoxied to the inner radius of the center core support mandrel. The AMOS simulations used a TDK PB $11 \mathrm{~b}$ ferrite model.

\section{SUMMARY}

An induction module has been designed that meets the stringent requirements of the TBNLC relativistic klystron. The demonstrated performance of stacked insulators was a critical factor in achieving a satisfactory design. An important feature of these insulators is their ability to with stand high field stress in the presence of intense electron beams. This allowed for a greatly simplified gap design for the specific application presented and can readily be applied to other induction module designs.

\section{ACKNOWLEDGMENTS}

The work was performed under the auspices of the U.S. Department of Energy by LINL under contract W-7405-ENG-48, LBNL under contract AC0376SF00098, and FAR under SBIR Grant DE-FG0396ER82179. S. Sampayan (LLNL) and M. Krogh (Allied Signal) provided helpful information on the performance and application of high-gradient insulators.

\section{REFERENCES}

[1] Juan M. Elizondo and A.E. Rodriguez, "Novel High Voltage Vacuum Surface Flashover Insulator Technology," Proceedings of the $X V$ th International Symposium on Discharges and Electrical Insuiation in Vacuum, Vde-Vertag, Berlin, Germany, pp. 198-202.

[2] S. Sampayan, et al.. "High-Performance Insulator Structures for Accelerator Applications", these proceedings.

[3] S. Sampayan, et al., Proceedings 1995 Particle Accelerator Conference, (IEEEE), New York, N.Y., pp. 1269-1271.

[4] M. Burns, et al., Proceedings 1991 Particle Accelerator Conference. (IEEE), New York, N.Y., pp. 2958-2960.

[5] T.L. Houck, et al., these proceedings

[6] S. Eylon, et al., these proceedings.

[7] T. Houck, et al., IEEE Trans. Plasma Sci., vol. 24, p. 938, 1996.

[8] R.J. Briggs, et al., Part. Acc., 18, pp.41-62. 1985.

[9] J.-S. Kim, et al., Proceedings 1993 Particle Accele-rator Conference, (IEEE), New York, N.Y., pp. 3288-3290.

[10] Birx, D., Phase II Final Report of Contract DAA H01-89-C-0201, 1991. 


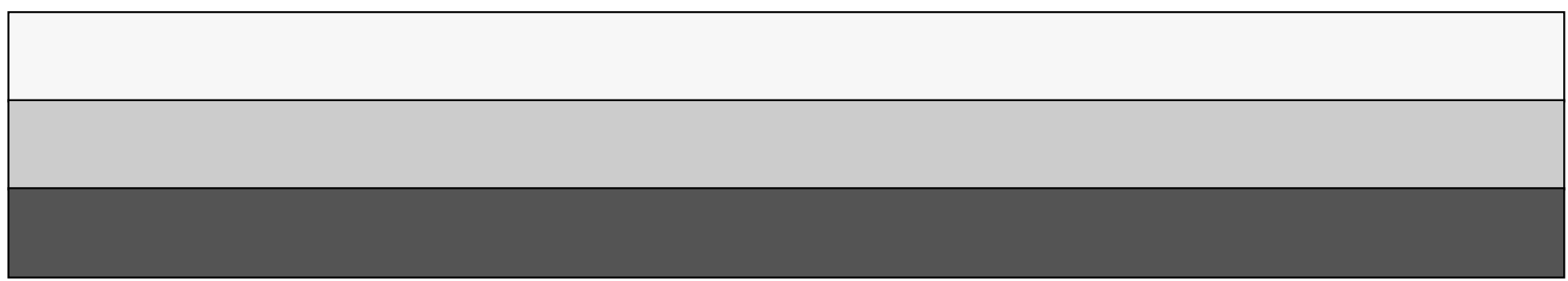

